\title{
BMJ Open Fast-food consumption and body mass index in children and adolescents: an international cross-sectional study
}

\author{
Irene Braithwaite, ${ }^{1}$ Alistair W Stewart, ${ }^{2}$ Robert J Hancox, ${ }^{3}$ Richard Beasley, ${ }^{1}$ \\ Rinki Murphy, ${ }^{4}$ Edwin A Mitchell, ${ }^{5}$ the ISAAC Phase Three Study Group
}

To cite: Braithwaite I, Stewart AW, Hancox RJ, et al. Fast-food consumption and body mass index in children and adolescents: an international crosssectional study. BMJ Open 2014:4:e005813. doi:10.1136/bmjopen-2014005813

\section{- Prepublication history for this paper is available online. To view these files please visit the journal online (http://dx.doi.org/10.1136/ bmjopen-2014-005813).}

Received 29 May 2014 Revised 18 November 2014 Accepted 19 November 2014

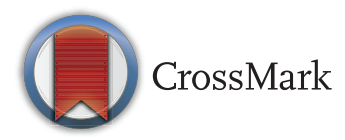

For numbered affiliations see end of article.

Correspondence to Dr Irene Braithwaite; irene. braithwaite@mrinz.ac.nz

\section{ABSTRACT}

Objective: To investigate whether reported fast-food consumption over the previous year is associated with higher childhood or adolescent body mass index (BMI).

Design: Secondary analysis from a multicentre, multicountry cross-sectional study (International Study of Asthma and Allergies in Children (ISAAC) Phase Three).

Subjects and methods: Parents/guardians of children aged 6-7 completed questionnaires which included questions about their children's asthma and allergies, fast-food consumption, height and weight. Adolescents aged 13-14 completed the same questionnaire. The questionnaire asked "In the past 12 months, how often on average did you (your child) eat fast-food/burgers?" The responses were infrequent (never/only occasionally), frequent (once/ twice a week) or very frequent (three or more times per week). A general linear mixed model was used to determine the association between BMI and fast-food consumption, adjusting for Gross National Income per capita by country, measurement type (whether heights/weights were reported or measured), age and sex.

Results: 72900 children (17 countries) and 199135 adolescents (36 countries) provided data. Frequent and very frequent fast-food consumption was reported in $23 \%$ and $4 \%$ of children, and $39 \%$ and $13 \%$ of adolescents, respectively. Children in the frequent and very frequent groups had a BMI that was 0.15 and $0.22 \mathrm{~kg} / \mathrm{m}^{2}$ higher than those in the infrequent group $(p<0.001)$. Male adolescents in the frequent and very frequent groups had a BMI that was 0.14 and $0.28 \mathrm{~kg} / \mathrm{m}^{2}$ lower than those in the infrequent group $(p<0.001)$. Female adolescents in the frequent and very frequent groups had a BMI that was $0.19 \mathrm{~kg} / \mathrm{m}^{2}$ lower than those in the infrequent group $(p<0.001)$.

Conclusions: Reported fast-food consumption is high in childhood and increases in adolescence. Compared with infrequent fast-food consumption, frequent and very frequent consumption is associated with a higher BMI in children. Owing to residual confounding, reverse causation and likely misreporting, the reverse association observed in adolescents should be interpreted with caution.

\section{Strengths and limitations of this study}

- In total, 199135 adolescents from 36 countries and 72900 children from 17 countries provided information on their height, weight and fast-food consumption.

- The majority were middle-income and lowincome countries from which previous data on the association of fast-food consumption and body mass index (BMI) had not been reported.

- There is an association between increasing frequency of fast-food consumption and higher BMls in 6-7-year-old children, but this association was reversed in adolescents.

- As this is a cross-sectional study, causality cannot be proven, but it provides evidence that among children from many different nations, fast-food consumption may contribute to weight gain.

- The reverse association observed in adolescents should be interpreted with caution, as the results may be affected by bias, particularly underreporting of fast-food consumption and reverse causation.

\section{INTRODUCTION}

The rising prevalence of childhood obesity is marked, ${ }^{12}$ and there are well-documented concerns about the future health implications of obesity in childhood. ${ }^{3-7}$ This problem has been identified in low-income and middleincome countries as well as affluent countries. ${ }^{8} 9$

While potential contributors to the problem of childhood obesity are considered to be multiple and complex, in many countries fast-food has been implicated due to its increasing availability, energy density and large portion sizes. ${ }^{10-13}$ Studies investigating associations between fast-food consumption in children and body mass index (BMI) have produced mixed results, some demonstrating small but significant associations between fast-food consumption and increased BMI, ${ }^{12}{ }^{14-17}$ while others have failed to demonstrate a significant association. ${ }^{18-20}$ In a systematic 
review of studies assessing the association between fast-food and obesity in 2008, Rosenheck noted that 'it is difficult to ascertain the true relationship between fastfood consumption and weight gain or obesity, as many confounding factors such as physical inactivity and less inhibited food consumption are independently associated with both fast-food consumption and weight gain or obesity' and that '... residual confounding from immeasurable lifestyle choices will always distort results garnered from observational study designs'. ${ }^{14}$

Additionally, Rosenheck commented on the sample sizes of the cross-sectional studies, where only one study enrolled more than 5000 participants, and in general enrolment was closer to the 1000 mark, potentially negatively impacting the power of the studies to effectively assess the association between fast-food consumption and weight/obesity. A cross-sectional study large enough to achieve sufficient power to determine an association between fast-food consumption and obesity AND adequately address issues of multiple confounding factors is likely to be logistically demanding and prohibitively costly. A secondary analysis of the data from the International Study of Asthma and Allergies in Childhood (ISAAC) Phase Three programme allows an international 'snapshot' of fast-food consumption and an assessment of the association between fast-food consumption and BMI in 72900 children from 17 countries and 199135 adolescents from 36 countries at a single point in time, using a simple universal question. While few confounding variables are taken into account, the large numbers involved give power to this analysis.

We hypothesised that there would be an association between greater fast-food consumption and higher BMI in both children and adolescents, and that this association would be observed worldwide.

\section{SUBJECTS AND METHODS}

The ISAAC Phase Three programme was designed to measure time trends in the prevalence and severity of asthma, rhinoconjunctivitis and eczema and to explore the relationship between lifestyle, other putative risk factors and the development of asthma and allergies. ${ }^{21}$ ISAAC Phase Three used the ISAAC Phase One standardised core questionnaire on symptoms of asthma, rhinoconjunctivitis and eczema. Phase Three provided an additional opportunity to explore the relationship between lifestyle factors such as fast-food consumption and BMI, as heights, weights and information on the frequency of fast-food consumption of participants were gathered in many centres through an optional environmental questionnaire that was answered by the parents of the children and by the adolescents themselves.

The ISAAC Phase One standardised core questionnaire and ISAAC Phase Three environmental questionnaire are on the ISAAC website: isaac.auckland.ac.nz
Main outcome variable: BMI

Height and weight were reported by the parents of the children, and were self-reported by adolescents. In some centres, each participant's height and weight were measured objectively; there were no standardised or specific instructions for doing this. BMI was calculated as weight $(\mathrm{kg}) /$ height $(\mathrm{m})^{2}$.

\section{Explanatory variables}

Fast-food consumption was established by asking participants to answer the following question: "In the past 12 months, how often, on average, did you [your child] eat the following?"

'Fast-food/Burgers' were listed as one option along with 14 other foodstuffs including meat, seafood, fruit and vegetables. The participants were asked to categorise their intake of each listed food as "Never or only occasionally"; "once or twice per week"; or "Three or more times a week." These responses were categorised as 'infrequent', 'frequent' and 'very frequent'. Each variable was examined separately for both age groups.

Country Gross National Index (GNI) was based on the 2006 World Bank of Gross National Income by country. The World Bank categories of high-income, high middle income, low middle income and low-income countries were dichotomised into 'high-income' (high and high middle income) and 'low-income' (low middle and low income) categories.

\section{Participants}

For children aged 6-7 years, data were submitted from 73 centres in 32 countries (214 706 participants). For adolescents aged 13-14 years, data were submitted from 122 centres in 53 countries (362 019 participants).

Centres that provided data on height, weight and fast-food consumption for at least $70 \%$ of participants were included in our analyses. Individuals without complete age, sex, fast-food consumption, height or weight data were excluded.

\section{Data cleaning}

To eliminate likely erroneous BMI data, we applied the following thresholds:

- For children in each centre, those in the top and bottom $0.5 \%$ of weights and heights, and those with heights less than $1 \mathrm{~m}$ were excluded. Children with a BMI less than $9 \mathrm{~kg} / \mathrm{m}^{2}$ and greater than $40 \mathrm{~kg} / \mathrm{m}^{2}$ were excluded.

- For adolescents in each centre, those in the top and bottom $0.5 \%$ of weights and heights, and those with heights less than $1.25 \mathrm{~m}$ were excluded. Adolescents with a BMI less than $10 \mathrm{~kg} / \mathrm{m}^{2}$ and greater than $45 \mathrm{~kg} / \mathrm{m}^{2}$ were excluded.

Following sequential application of the exclusion and data cleaning criteria described above, 72900 children (30 centres/17 countries) and 199135 adolescents (74 centres/36 countries) were included in the final analysis (figure 1). Parents provided heights and weights for 

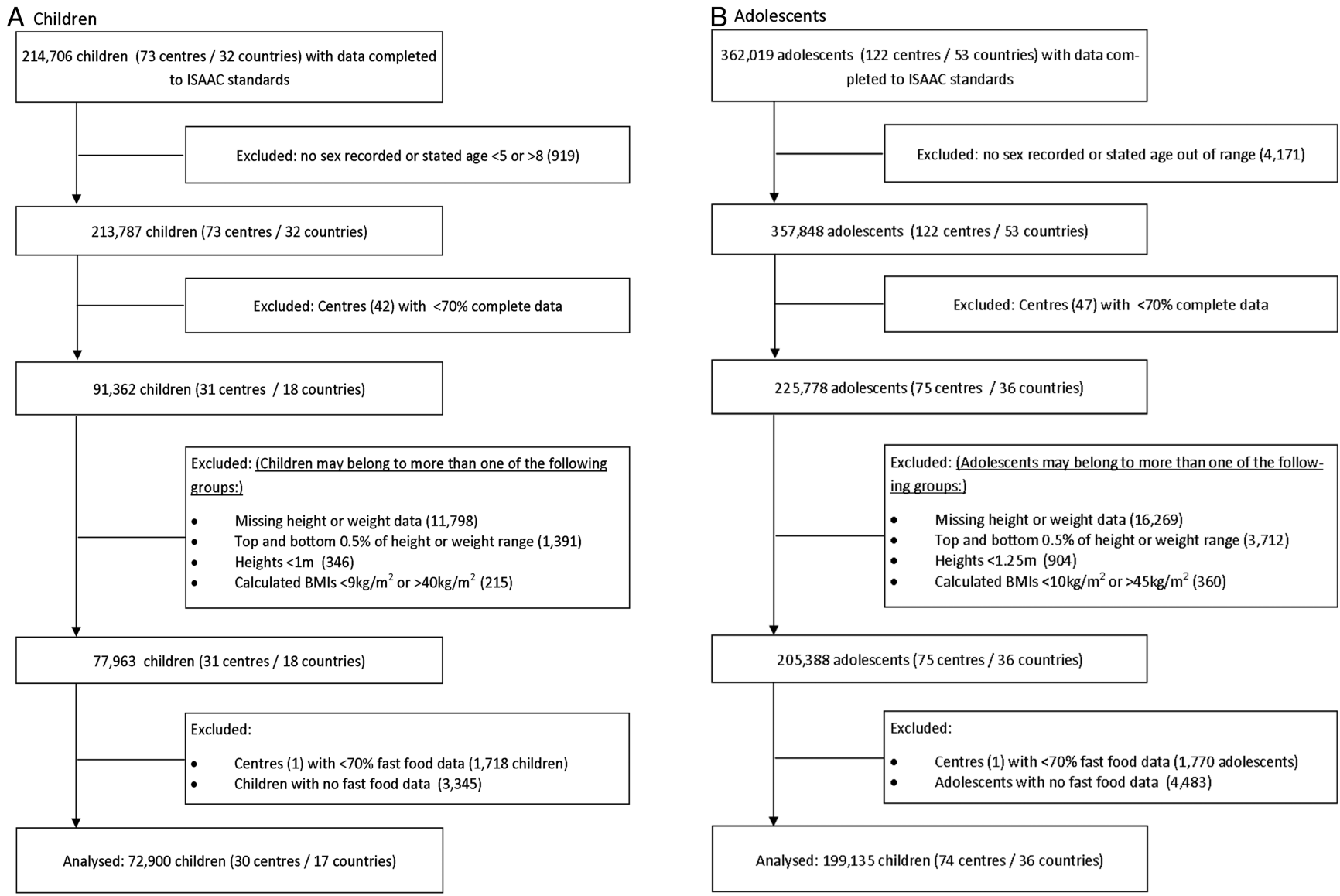

Figure 1 Flow of participants through the study. Children are represented in (A) and adolescents in (B) (BMI, body mass index).

60027 children, while 12873 children had their heights and weights measured. In total, 154624 adolescents provided self-reported height and weight while 44511 adolescents had measured heights and weights.

\section{STATISTICAL ANALYSIS}

BMI was assessed separately for each age group using a general linear mixed model with centre as a random effect and GNI for each country (low and high), the individual's age, sex, measurement type (reported or measured) and fast-food consumption ('infrequent', 'frequent', 'very frequent') as fixed effects. The BMI values reported are the modelled means for those who reported infrequent fast-food consumption in the children and adolescent groups, respectively.

In the adolescent group, statistically significant interactions were found between sex and fast-food consumption, and measurement type and fast-food consumption. There was also an interaction found between country GNI and fast-food consumption. Consequently, analyses were conducted separately for each sex, measured height and weight data only, and GNI categories. No similar interactions were found in the children's group, but there were sufficient numbers to analyse each sex separately, which we elected to do.

\section{RESULTS}

\section{Fast-food consumption}

Only $22.6 \%$ of children reported frequent fast-food consumption and $4.2 \%$ reported very frequent fast-food consumption. Combined frequent and very frequent fast-food consumption in each country ranged from $10 \%$ in Poland to $63 \%$ in South Korea (figure 2A).

In total, $38.7 \%$ of adolescents reported frequent fast-food consumption and $12.6 \%$ reported very frequent consumption. Frequent and very frequent fast-food consumption ranged from $15 \%$ in Indonesia to $79 \%$ in South Africa (figure 2B).

\section{Fast-food consumption and BMI \\ Children}

Figure 3A shows the difference in BMI between children with infrequent fast-food consumption and those with frequent and very frequent fast-food consumption in each centre.

The estimated mean BMIs in children reporting infrequent fast-food consumption were 16.20 and $16.51 \mathrm{~kg} / \mathrm{m}^{2}$ for ages 6 and 7, respectively. After controlling for country GNI, centre, age and measurement type, there was a statistically significant association between frequent and very frequent fast-food consumption and higher BMI with an apparent dose-response effect $(+0.15$ and 


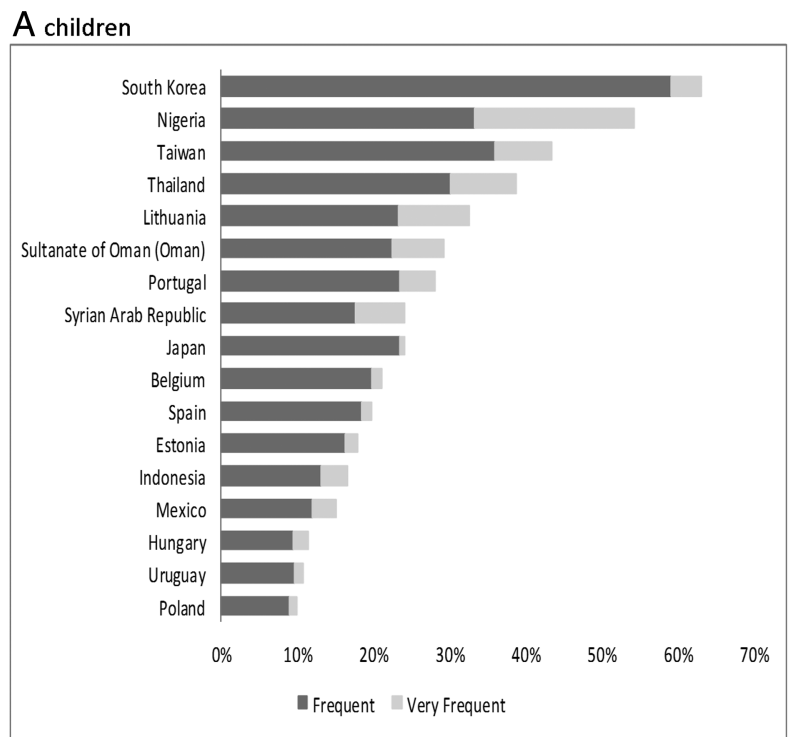

B adolescents

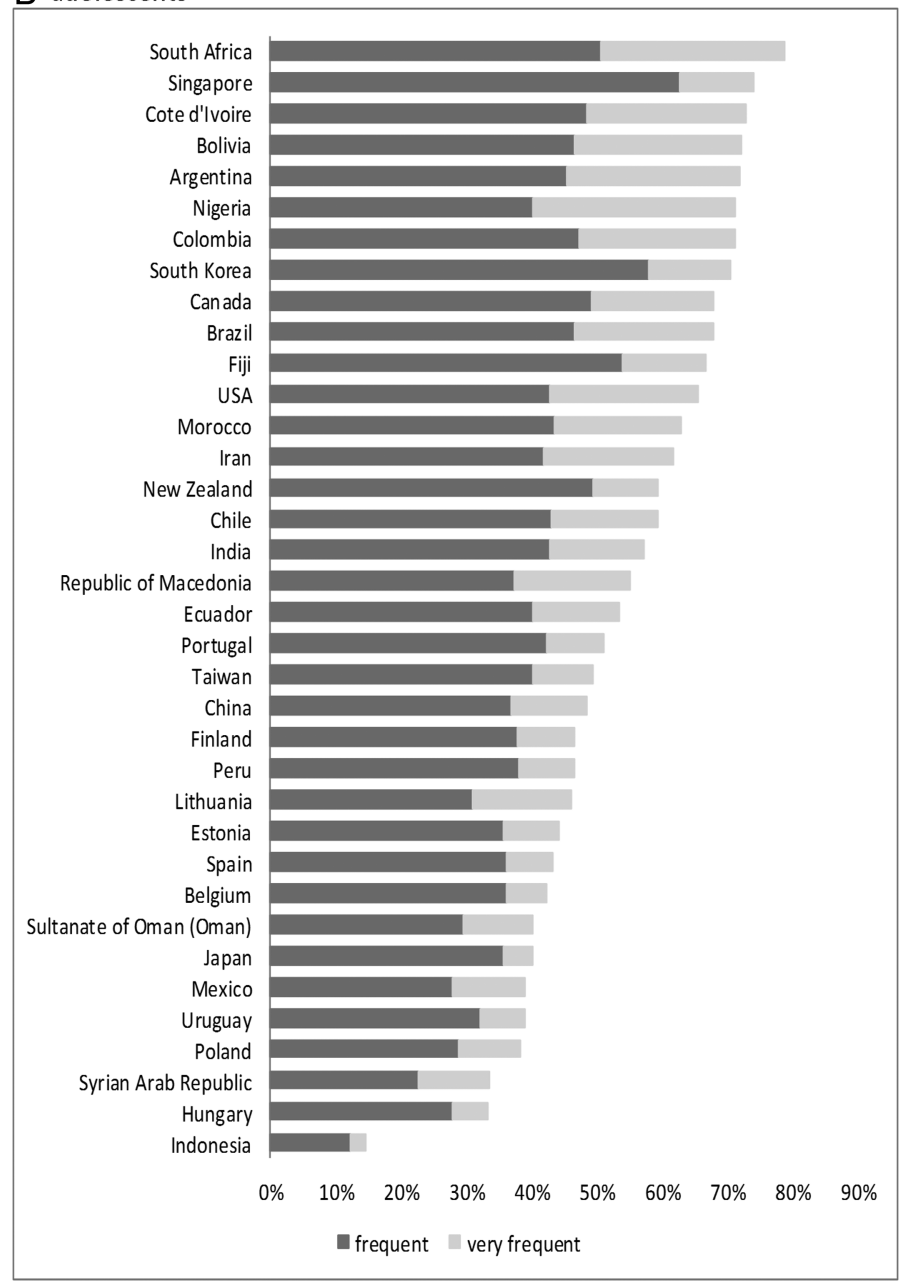

Figure 2 Reported frequency of fast-food consumption by study participants. Children are represented in (A) and adolescents in (B).

$+0.22 \mathrm{~kg} / \mathrm{m}^{2}$ for frequent and very frequent fast-food consumption, respectively; table 1). There was no statistically significant interaction between GNI and fast-food consumption in this age group $(\mathrm{p}=0.06)$.

When boys and girls were analysed separately, both sexes had a significant positive association between frequent and very frequent fast-food consumption (table 1).

\section{Adolescents}

Figure 3B shows the difference in BMI between adolescents with infrequent fast-food consumption and those with frequent and very frequent fast-food consumption in each centre.

In male adolescents, the estimated mean BMIs for those reporting infrequent fast-food consumption were 19.74 and $20.02 \mathrm{~kg} / \mathrm{m}^{2}$ for ages 13 and 14 , respectively. After controlling for country GNI, centre, age and measurement type, lower BMIs were significantly associated with greater fast-food consumption (table 1). There was a statistically significant interaction between fast-food consumption and GNI. In low-GNI countries, the frequency of fast-food consumption had no association with BMI $\left(+0.01\right.$ and $-0.03 \mathrm{~kg} / \mathrm{m}^{2}$ in the frequent and very frequent groups, respectively $(\mathrm{p}=0.89$ and 0.56$)$ ). In high-GNI countries, lower BMIs were associated with greater fast-food consumption $\left(-0.21\right.$ and $-0.42 \mathrm{~kg} / \mathrm{m}^{2}$ in the frequent and very frequent groups, respectively $(\mathrm{p}<0.001$ in both groups) $)$.

When analyses were restricted to the 20384 male adolescents who had measured height and weight data, there was a tendency towards a lower BMI with higher fast-food consumption, but this was not statistically significant $\left(-0.03\right.$ and $-0.11 \mathrm{~kg} / \mathrm{m}^{2}$ in the frequent and very frequent groups, respectively $(p=0.24)$ ).

In female adolescents, the estimated mean BMIs for those reporting infrequent fast-food consumption were 19.56 and $19.98 \mathrm{~kg} / \mathrm{m}^{2}$ for ages 13 and 14 , respectively. Lower BMIs were associated with greater fast-food consumption and this was statistically significant. There was a statistically significant interaction between fast-food consumption and GNI. Both low-GNI and high-GNI countries had an association between increasing fast-food consumption and BMI (low-GNI countries -0.10 and $-0.11 \mathrm{~kg} / \mathrm{m}^{2}$ in the frequent and very frequent groups, respectively $(\mathrm{p}=0.03$ and 0.01$)$, and high-GNI countries -0.24 and $-0.22 \mathrm{~kg} / \mathrm{m}^{2}$ in the 
A

Children

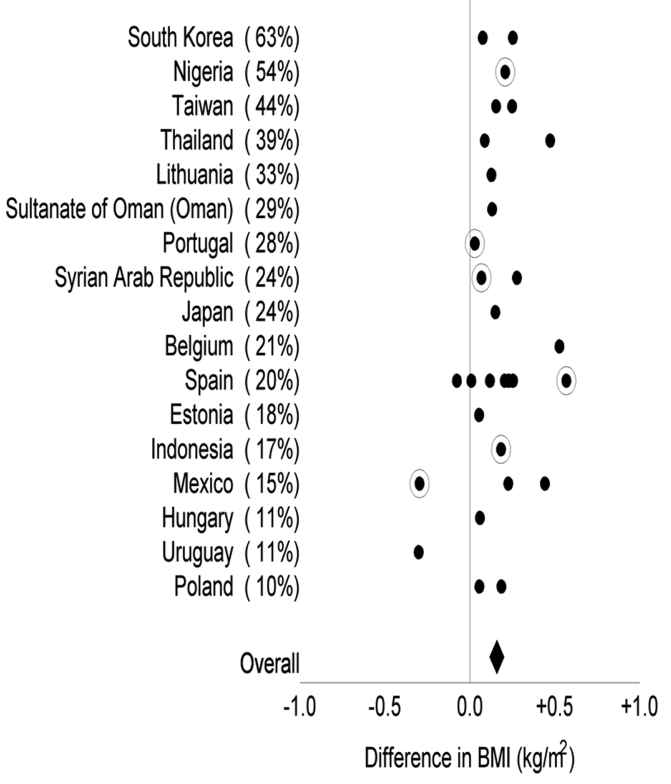

B
Adolescents

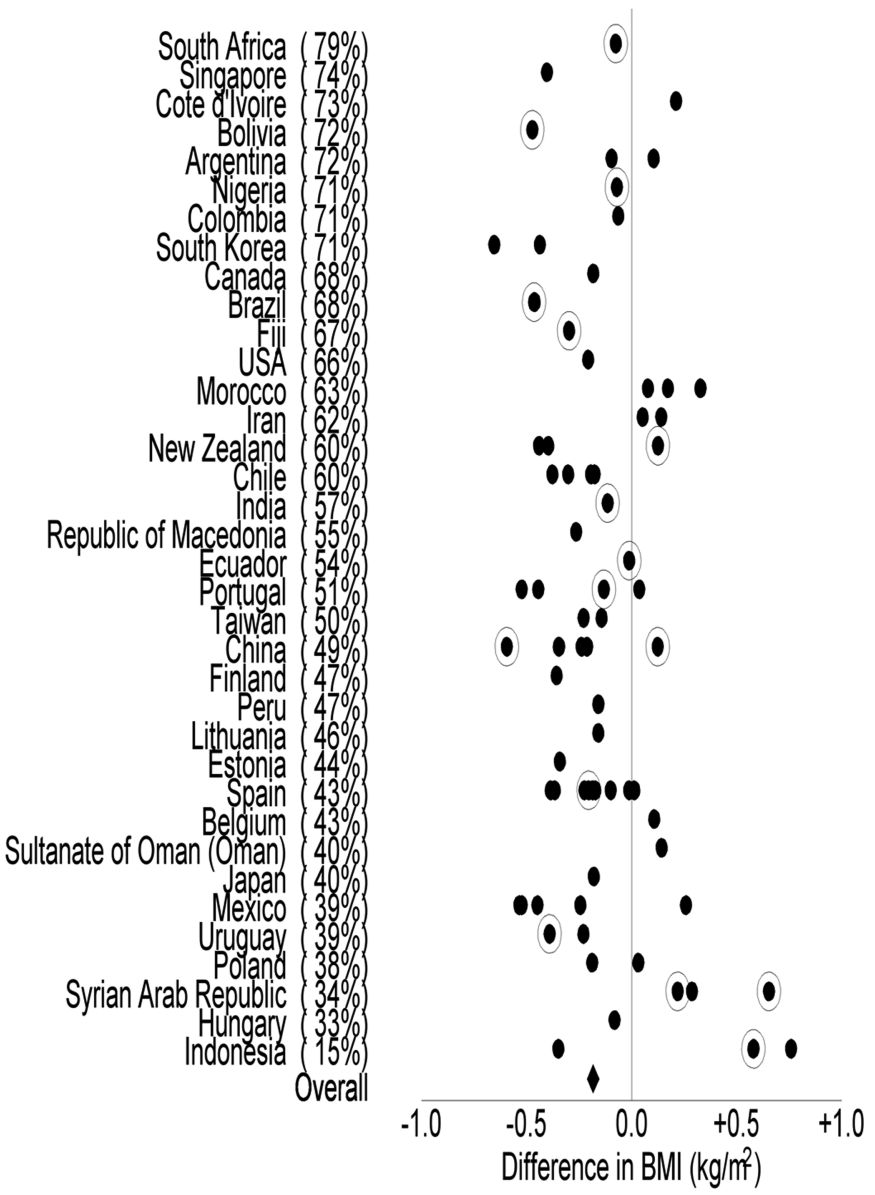

Figure 3 The difference in body mass index (BMI) of study participants who consumed fast-food frequently and very frequently compared to infrequent fast-food consumption. Children are represented in (A) and adolescents in (B). For each country, the proportion of participants who consume fast-food frequently or very frequently is shown in parentheses. Those centres with reported height and weights are shown with filled-in circles, and those centres that measured heights and weights are shown with hollowed circles.

frequent and very frequent groups, respectively $(\mathrm{p}<0.0001$ in both cases)).

When analyses were restricted to the 24127 female adolescents who had measured height and weight data, those who ate fast-food frequently or very frequently had lower BMIs and this was statistically significant (table 1).

\section{DISCUSSION}

This international study has identified that 6-7-year-old children who consumed fast-food frequently had higher BMIs than those who consumed fast-food infrequently. This association was independent of the affluence of the country and of similar magnitude in boys and girls. By contrast, adolescents who self-reported that they frequently ate fast-foods tended to have lower BMIs, with the exception of male adolescents from low-GNI countries, where there was no association between fast-food consumption and BMI. We have also found that up to $25 \%$ of children worldwide consume fast-food frequently or very frequently, and this increases to over $50 \%$ in the adolescent age group.

\section{Children}

Our results in children are consistent with those of Shan et $a l^{22}$ who found that 'Western fast-food' and 'snack food' were associated with overweight and obesity among children aged 2-18 years in Beijing. However, in New Zealand, Duncan $e t a l^{20}$ found that low levels of physical activity, skipping breakfast and insufficient sleep on weekdays were associated with increased adiposity in 5-11-year-olds, but that fast-food consumption was not. The magnitude of the association between fast-food consumption and BMI in children was small (mean BMI values 0.15 and $0.22 \mathrm{~kg} / \mathrm{m}^{2}$ higher in frequent and very frequent consumers compared to infrequent consumers), and the clinical significance of this is uncertain. Given the long-term consequences of overweight and obesity in childhood, even a small change in mean BMI in a population could be of major public health significance.

An observational study such as this cannot attribute causality. The association we have found between fast-food consumption and BMI in children could be 
Table 1 Association between fast-food consumption and BMI (SE) of study participants after adjustment for GNI

\begin{tabular}{|c|c|c|c|c|}
\hline & \multirow[b]{2}{*}{$\begin{array}{l}\text { Estimated mean BMI } \\
\left(\mathrm{kg} / \mathrm{m}^{2}\right) \text { infrequent } \\
\text { fast-food consumption }\end{array}$} & \multicolumn{3}{|c|}{$\begin{array}{l}\text { Difference in mean BMI }\left(\mathrm{kg} / \mathrm{m}^{2}\right) \text { compared with infrequent } \\
\text { fast-food consumption }\end{array}$} \\
\hline & & $\begin{array}{l}\text { Frequent fast-food } \\
\text { consumption: } \\
\text { mean (SE) }\end{array}$ & $\begin{array}{l}\text { Very frequent fast-food } \\
\text { consumption: } \\
\text { mean (SE) }\end{array}$ & p Value \\
\hline Children (N=72 900) & 16.51 & $+0.15(0.02)$ & $+0.22(0.05)$ & $<0.001$ \\
\hline Male $(\mathrm{N}=36778)$ & 16.53 & $+0.16(0.03)$ & $+0.24(0.06)$ & $<0.001$ \\
\hline Female $(\mathrm{N}=36$ 122) & 16.39 & $+0.14(0.03)$ & $+0.20(0.07)$ & $<0.001$ \\
\hline \multicolumn{5}{|l|}{ Adolescents } \\
\hline Male $(\mathrm{N}=98 \mathrm{794})$ & 20.02 & $-0.14(0.02)$ & $-0.28(0.03)$ & $<0.001$ \\
\hline Female $(\mathrm{N}=100341)$ & 19.98 & $-0.19(0.02)$ & $-0.19(0.03)$ & $<0.001$ \\
\hline \multicolumn{5}{|c|}{ Participants with measured height and weight data } \\
\hline Children $(\mathrm{N}=12 \mathrm{873})$ & 15.88 & $+0.14(0.05)$ & $+0.13(0.08)$ & 0.02 \\
\hline \multicolumn{5}{|l|}{ Adolescents } \\
\hline Male (N=20 384) & 19.67 & $-0.03(0.05)$ & $-0.11(0.07)$ & 0.24 \\
\hline Female $(\mathrm{N}=24127)$ & 20.15 & $-0.15(0.05)$ & $-0.09(0.06)$ & 0.004 \\
\hline
\end{tabular}

${ }^{*}$ Estimated BMls for children aged 7 years and adolescents aged 14 years.

$\mathrm{tp}$ Value is a joint test of whether the differences in BMls for frequent and very frequent fast-food consumption relative to infrequent fast-food consumption are 0 .

BMI, body mass index; GNI, Gross National Index.

due to other specific dietary factors that have been shown to be associated with fast-food consumption, such as higher fat intake, greater consumption of sugary drinks, fewer fruits and non-starchy vegetables. ${ }^{11}$ Alternatively, fast-food consumption may be a marker of other factors that influence BMI such as parental BMI, individual socioeconomic circumstances or patterns of activity and inactivity.

\section{Adolescents}

In our analysis, self-reported frequent fast-food consumption was associated with a lower BMI in adolescents, with stronger association in higher GNI countries. As far as we are aware, no other studies have demonstrated a lower BMI with higher fast-food consumption in adolescence and our findings appear to be in stark contrast to other research findings from high-GNI countries. One study showed that increasing fast-food consumption in American adolescents was associated with increased weight gain from adolescence to adulthood. ${ }^{12}$ Another study found that American adolescents who consumed greater quantities of fried food away from home were heavier, ${ }^{23}$ and, in a further American study, increasing frequency of eating quick-service food was associated with increasing z-BMI in female adolescents. ${ }^{17} \mathrm{~A}$ UK study found that increased visits to fast-food outlets were associated with higher BMI SD scores in teenagers. ${ }^{24}$ In three of these studies, heights and weights were measured to preset standards by trained investigators, ${ }^{12} 1724$ whereas heights and weights of our adolescent participants were mostly self-reported. It is possible that in our study some of the larger participants, particularly from body image conscious countries or cultures, may have under-reported their weights. In a study evaluating the correlation of measured versus self-reported heights and weights in adolescents, Brener et al found that their study subjects tended to over-report their height by 2.7 inches $(6.9 \mathrm{~cm})$ on average, and to under-report their weight by 3.5 pounds $(1.6 \mathrm{~kg}$ ) on average, resulting in a BMI understated by $2.6 \mathrm{~kg} / \mathrm{m}^{2}$ when compared to measured values. White adolescents were most likely to overreport their height and female adolescents were more likely to under-report their weight. ${ }^{25}$ Similarly, Danubio et $a t^{26}$ found that height was over-estimated in boys and girls (2.1 and $2.8 \mathrm{~cm}$, respectively), and that weight was understated (1.5 kg in boys and $1.9 \mathrm{~kg}$ in girls). Rasmussen $e t a l^{27}$ reported that in the COMPASS study, boys and girls who wished to be leaner under-reported their weight and BMI more than participants who were satisfied with their body size. When we restricted our analysis to measured height and weight data only, the association between higher fast-food consumption and lower BMI was no longer observed in male adolescents, but the association between higher rates of fast-food consumption and lower BMI persisted in female adolescents. We need to consider the likelihood that, owing to the perception of the negative effects of fast-food consumption, adolescents who are overweight or obese are likely to have under-reported their actual fast-food consumption. In a review of validation studies on energy intake reporting in children and adolescents, Livingstone and Robson found an increase in underreporting of energy intake as age and BMI increased, with 14\%, 25\% and $40 \%$ of energy intake underreported in obese 6-year-olds, 10-year-olds and adolescents, respectively. ${ }^{28}$ Finally, it is possible that our results are influenced by a degree of reverse causation where those participants who are already overweight or obese are avoiding fast-foods in order to reduce their body weight. 


\section{Fast-food consumption}

This study has shown that up to $25 \%$ of children worldwide consume fast-food frequently or very frequently, and this increases to over $50 \%$ in the adolescent age group. This is consistent with results of previous studies, particularly those based in the USA and the UK. ${ }^{11} 2930$ This study has also highlighted the unexpectedly high proportion of fast-food consumption in both age groups in many developing countries, for which data have not previously been available. In particular, high prevalence of fast-food consumption was observed in centres in Latin America and Asia, which was similar in magnitude to that observed in the USA and Western Europe. Importantly, we have also shown that the association between fast-food consumption and higher BMI in children persists among those from both affluent and less affluent countries.

Cohort studies have demonstrated that high consumption of fast-food at first assessment is associated with higher BMIs later in childhood or adult life. ${ }^{12}{ }^{24}$ If this is the case, despite an apparently lower BMI with more frequent fast-food consumption in the adolescent group, the high proportion of adolescents eating fast-food frequently is a matter of concern, as fast-food consumption has been directly linked with insulin resistance, hypertension and other health sequelae. ${ }^{31}$

\section{Strengths and limitations}

The major strengths of this study were its size and multicentre structure, with 199135 adolescents from 36 countries and 72900 children from 17 countries surveyed. Many of the centres were from middle-income and lowincome countries from which previous data on the association between fast-food consumption and BMI had not been reported.

The main limitation to this study is the cross-sectional design which allows identification of associations, but not of temporal sequence or causality. The assessment of participants' heights and weights and their fast-food consumption was primarily undertaken by a questionnaire which raises the possibility of misclassification error, particularly with respect to the parent-reported weights of their children and self-reported weights of the adolescents, thereby influencing the calculated BMI. It is also possible that parents and adolescents may have misreported fast-food consumption.

A further consideration is the interpretation of the question about the consumption of burgers/fast-foods. While a 'burger' is almost universally understood, a 'fastfood' can be interpreted in a number of ways, including foodstuffs from global restaurant chains, smaller nonfranchised food stores, street vendors and even frozen meals heated and served at home. Without knowing the exact kind of fast-food consumed, we can make no assessment of the nutritional content or energy density of the food in question. Additionally, while the questionnaire asked about the frequency of burgers/fast-food consumption, we have no indication of portion sizes, or if it was accompanied by other items such as sugarsweetened beverages.

Finally, centres that objectively measured heights and weights received no standardised instructions for doing this. We have controlled for GNI, centre, measurement type and sex in our analysis; however, we have no data available on individual socioeconomic status or parental BMI which could potentially affect young peoples' BMI, and nor did we control for physical activity/inactivity of the participants.

\section{Conclusions}

This cross-sectional study has found that one-quarter of children and half of the adolescents consume fast-food frequently or very frequently. Additionally, there was an association between a high frequency of fast-food consumption and higher BMIs in 6-7-year-old children, but this association was reversed in adolescents. As this is an observational study, causality cannot be proven; however, it provides evidence that among children from many different nations, fast-food consumption may contribute to weight gain. This reverse association observed in adolescents should be interpreted with caution, as the results may be affected by bias, particularly the under-reporting of fast-food consumption and reverse causation.

\section{Author affiliations}

${ }^{1}$ Medical Research Institute of New Zealand, Wellington, New Zealand

${ }^{2}$ School of Population Health, The University of Auckland, Auckland, New Zealand

${ }^{3}$ Department of Preventive \& Social Medicine, Dunedin School of Medicine, University of Otago, Dunedin, New Zealand

${ }^{4}$ Faculty of Medicine and Health Sciences, Department of Medicine,

The University of Auckland, Auckland, New Zealand

${ }^{5}$ Faculty of Medicine and Health Sciences, Department of Paediatrics: Child and Youth Health, The University of Auckland, Auckland, New Zealand

Collaborators The authors are grateful to the children and parents who participated in the ISAAC Phase Three Study. They are also grateful to the ISAAC Steering Committee, the ISAAC International Data Centre and ISAAC Phase Three Principal Investigators and Regional and National coordinators as listed below. ISAAC Steering Committee: N Aït-Khaled* (International Union Against Tuberculosis and Lung Diseases, Paris, France); HR Anderson (Division of Community Health Sciences, St Georges, University of London, London, UK); MI Asher (Department of Paediatrics: Child and Youth Health, Faculty of Medical and Health Sciences, The University of Auckland, New Zealand); RB* (Medical Research Institute of New Zealand, Wellington, New Zealand); B Björkstén ${ }^{\star}$ (Institute of Environmental Medicine, Karolinska Institutet, Stockholm, Sweden); B Brunekreef (Institute of Risk Assessment Science, Universiteit Utrecht, Netherlands); J Crane (Wellington Asthma Research Group, Wellington School of Medicine, New Zealand); P Ellwood (Department of Paediatrics: Child and Youth Health, Faculty of Medical and Health Sciences, The University of Auckland, New Zealand); C Flohr (Department of Paediatric Allergy and Dermatology, St Johns Institute of dermatology, St Thomas' Hospital, London, UK); S Foliaki* (Centre for Public Health Research, Massey University, Wellington, New Zealand); F Forastiere (Department of Epidemiology, Local Health authority Rome, Italy); L García-Marcos (Respiratory Medicine and Allergy Units, 'Virgen de la Arrixaca' University Children's Hospital, University of Murcia, Spain); U Keil* (Institut für Epidemiologie und Sozialmedizin, Universität Münster, Germany); CKW Lai $^{\star}$ (Department of Medicine and Therapeutics, The Chinese University of Hong Kong, SAR China); J Mallol* (Department of Paediatric Respiratory Medicine, University of Santiago de Chile, Chile); EAM (Department of 
Paediatrics: Child and Youth Health, Faculty of Medical and Health Sciences, The University of Auckland, New Zealand); S Montefort* (Department of Medicine, University of Malta, Malta), J Odhiambo† (Centre Respiratory Diseases Research Unit, Kenya Medical Research Institute, Nairobi, Kenya); N Pearce (Department of Medical Statistics, Faculty Epidemiology and Public Health, London School of Hygiene and Tropical Medicine, London, UK); CF Robertson (Murdoch Children's Research Institute, Melbourne, Australia); AWS (Population Health, Faculty of Medical and Health Sciences, The University of Auckland, New Zealand); D Strachan (Division of Community Health Sciences, St Georges, University of London, London, UK); E von Mutius (Dr von Haunerschen Kinderklinik de Universität München, Germany); SK Weiland $†$ (Institute of Epidemiology, University of Ulm, Germany); G Weinmayr (Institute of Epidemiology and Medical Biometry, University of UIm, Germany); H Williams (Centre for Evidence Based Dermatology, Queen's Medical Centre, University Hospital, Nottingham, UK); G Wong (Department of Paediatrics, Prince of Wales Hospital, Hong Kong, SAR China).

${ }^{*}$ Regional coordinators; †Deceased

ISAAC International Data Centre: MI Asher, TO Clayton, E Ellwood, P Ellwood, EAM, Department of Paediatrics: Child and Youth Health, and AWS, School of Population Health, Faculty of Medical and Health Sciences, The University of Auckland, New Zealand.

ISAAC Phase Three Study Group: ISAAC Principal Investigators-Argentina: CE Baena-Cagnani* (Córdoba), M Gómez (Salta); Belgium: J Weyler (Antwerp); Bolivia: R Pinto-Vargas* (Santa Cruz); Brazil: AJLA Cunha (Nova Iguaçu), L de Freitas Souza (Vitória da Conquista); Canada: A Ferguson (Vancouver); Chile: L Amareles (Punta Arenas), P Aguilar (South Santiago), LAV Benavides (Calama), A Contreras (Chiloe); China: Y-Z Chen* (Beijing, Tong Zhou), 0 Kunii (Tibet), Q Li Pan (Wulumuqi), N-S Zhong (Guangzhou); G Wong (Hong Kong 13-14 years); Colombia: AM Cepeda (Barranquilla); Cote d'Ivoire: BN Koffi* (Urban Cote d'Ivoire); Ecuador: C Bustos (Guayaquil); Estonia: M-A Riikjärv* (Tallinn); Fiji: R Sa’aga-Banuve (Suva); Finland: J Pekkanen* (Kuopio County); Former Yugoslav Republic of Macedonia (FYROM): E Vlaski* (Skopje); Hungary: G Zsigmond* (Svábhegy); India: SK Sharma (New Delhi (7)); Indonesia: CB Kartasasmita (Bandung), P Konthen (Bali), W Suprihati (Semarang); Iran: M-R Masjedi† (Tehran, Rasht); Japan: H Odajima (Fukuoka); Lithuania: J Kudzyte* (Kaunas); Mexico: M Barragán-Meijueiro (Ciudad de México (3)), BE Del-Río-Navarro (Ciudad de México (1)), FJ Linares-Zapién (Toluca), N Ramírez-Chanona (Ciudad de México (4)), S Romero-Tapia (Villahermosa); Morocco: Z Bouayad ${ }^{\star}$ (Boulmene, Casablanca, Marrakech); New Zealand: R MacKay (Nelson), C Moyes (Bay of Plenty), P Pattemore (Christchurch); Nigeria: BO Onadeko (Ibadan); Peru: P Chiarella* (Lima); Poland: A Brêborowicz (Poznan), G Lis ${ }^{\star}$ (Kraków); Portugal: R Câmara (Funchal), JM Lopes dos Santos (Porto), C Nunes (Portimao), JE Rosado Pinto* (Lisbon); Singapore: DYT Goh (Singapore); South Africa: HJ Zar ${ }^{\star}$ (Cape Town); South Korea: H-B Lee* (Provincial Korea, Seoul); Spain: A Blanco-Quirós (Valladolid), RM Busquets (Barcelona), I Carvajal-Urueña (Asturias), G García-Hernández (Madrid), L García-Marcos* (Cartagena), C González Díaz (Bilbao), A López-Silvarrey Varela (A Coruña), MM Morales-Suárez-Varela (Valencia), EG Pérez-Yarza (San Sebastián); Sultanate of Oman: 0 Al-Rawas ${ }^{\star}$ (Al-Khod); Syrian Arab Republic: S Mohammad* (Tartous), Y Mohammad (Lattakia), K Tabbah (Aleppo); Taiwan: J-L Huang* (Taipei), C-C Kao (Taoyuan); Thailand: M Trakultivakorn (Chiang Mai), P Vichyanond (Bangkok); USA: HH Windom (Sarasota); Uruguay: D Holgado* (Montevideo), MC Lapides (Paysandú). ${ }^{*}$ National Coordinator.

ISAAC Phase Three National Coordinators not identified above-Brazil: D Solé; Canada: M Sears; Chile: V Aguirre; Fiji: L Waqatakirewa; India: J Shah; Indonesia: K Baratawidjaja; Japan: S Nishima; Mexico: M Baeza-Bacab; New Zealand: MI Asher; Singapore: B-W Lee.

Contributors AWS had access to all the data on the study and takes responsibility for the integrity of the data and accuracy of the data analysis; he was also involved in statistical analysis. All authors were involved in the study concept and design; critical revision of the manuscript for important intellectual content; and administrative, technical and material support. The ISAAC steering committee was involved in the acquisition of data. IB contributed to the drafting of the manuscript. EAM obtained funding and was involved in study supervision.

Funding EAM and IB are supported by Cure-Kids NZ.
Competing interests None.

Ethics approval Ethical approval was obtained for the original ISAAC Phase Three study, and permission was gained to use the data from ISAAC Phase Three through agreement with the ISAAC Phase Three Steering Committee.

Provenance and peer review Not commissioned; externally peer reviewed.

Data sharing statement Information with respect to all ISAAC studies, including methods, data gathering and results is available on the ISAAC website: isaac.auckland.ac.nz/.

Open Access This is an Open Access article distributed in accordance with the Creative Commons Attribution Non Commercial (CC BY-NC 4.0) license, which permits others to distribute, remix, adapt, build upon this work noncommercially, and license their derivative works on different terms, provided the original work is properly cited and the use is non-commercial. See: http:// creativecommons.org/licenses/by-nc/4.0/

\section{REFERENCES}

1. Hedley AA, Ogden CL, Johnson CL, et al. Prevalence of overweight and obesity among US children, adolescents, and adults, 19992002. JAMA 2004;291:2847-50.

2. Wang $\mathrm{Y}$, Lobstein T. Worldwide trends in childhood overweight and obesity. Int J Pediatr Obes 2006;1:11-25.

3. Franks PW, Hanson RL, Knowler WC, et al. Childhood obesity, other cardiovascular risk factors, and premature death. $N$ Engl J Med 2010;362:485-93.

4. Sinha R, Fisch G, Teague B, et al. Prevalence of impaired glucose tolerance among children and adolescents with marked obesity. N Engl J Med 2002;346:802-10.

5. Bibbins-Domingo K, Coxson P, Pletcher MJ, et al. Adolescent overweight and future adult coronary heart disease. $N$ Engl J Med 2007;357:2371-9.

6. Baker JL, Olsen LW, Sørensen TI. Childhood body-mass index and the risk of coronary heart disease in adulthood. $N$ Engl J Med 2007;357:2329-37.

7. Gunnell DJ, Frankel SJ, Nanchahal K, et al. Childhood obesity and adult cardiovascular mortality: a 57-y follow-up study based on the Boyd Orr cohort. Am J Clin Nutr 1998;67:1111-18.

8. Hossain P, Kawar B, El Nahas M. Obesity and diabetes in the developing world-a growing challenge. $N$ Engl J Med 2007;356:213-15

9. Wang $\mathrm{Y}, \mathrm{Mi} \mathrm{J}$, Shan $\mathrm{XY}$, et al. Is China facing an obesity epidemic and the consequences? The trends in obesity and chronic disease in China. Int $J$ Obes (Lond) 2007;31:177-88.

10. Alheritiere A, Montois S, Galinski M, et al. Worldwide relation between the number of McDonald's restaurants and the prevalence of obesity. J Intern Med 2013;274:610-11.

11. Bowman SA, Gortmaker SL, Ebbeling CB, et al. Effects of fast-food consumption on energy intake and diet quality among children in a national household survey. Pediatrics 2004;113(1 Pt 1):112-18.

12. Niemeier HM, Raynor HA, Lloyd-Richardson EE, et al. Fast food consumption and breakfast skipping: predictors of weight gain from adolescence to adulthood in a nationally representative sample. $J$ Adolesc Health 2006;39:842-9.

13. Larson NI, Story MT, Nelson MC. Neighborhood environments: disparities in access to healthy foods in the U.S. Am J Prev Med 2009;36:74-81.

14. Rosenheck R. Fast food consumption and increased caloric intake: a systematic review of a trajectory towards weight gain and obesity risk. Obes Rev 2008;9:535-47.

15. Taveras EM, Berkey CS, Rifas-Shiman SL, et al. Association of consumption of fried food away from home with body mass index and diet quality in older children and adolescents. Pediatrics 2005;116:e518-24.

16. Duffey KJ, Gordon-Larsen P, Jacobs DR Jr, et al. Differential associations of fast food and restaurant food consumption with 3-y change in body mass index: the Coronary Artery Risk Development in Young Adults Study. Am J Clin Nutr 2007;85:201-8.

17. Thompson OM, Ballew $\mathrm{C}$, Resnicow $\mathrm{K}$, et al. Food purchased away from home as a predictor of change in BMI Z-score among girls. Int J Obes Relat Metab Disord 2004;28:282-9.

18. Boutelle KN, Fulkerson JA, Neumark-Sztainer D, et al. Fast food for family meals: relationships with parent and adolescent food intake, home food availability and weight status. Public Health Nutr 2007;10:16-23.

19. French SA, Story M, Neumark-Sztainer D, et al. Fast food restaurant use among adolescents: associations with nutrient intake, food 
choices and behavioral and psychosocial variables. Int J Obes Relat Metab Disord 2001;25:1823-33.

20. Duncan JS, Schofield G, Duncan EK, et al. Risk factors for excess body fatness in New Zealand children. Asia Pac J Clin Nutr 2008;17:138-47.

21. Ellwood P, Asher MI, Beasley R, et al. The international study of asthma and allergies in childhood (ISAAC): phase three rationale and methods. Int $J$ Tuberc Lung Dis 2005;9:10-16.

22. Shan $\mathrm{XY}, \mathrm{Xi} \mathrm{B}, \mathrm{Cheng} \mathrm{H}$, et al. Prevalence and behavioral risk factors of overweight and obesity among children aged 2-18 in Beijing, China. Int J Pediatr Obes 2010;5:383-9.

23. Taveras EM. Association of consumption of fried food away from home with body mass index and diet quality in older children and adolescents. Pediatrics 2005;116:e518-24.

24. Fraser LK, Edwards KL, Cade JE, et al. Fast food, other food choices and body mass index in teenagers in the United Kingdom (ALSPAC): a structural equation modelling approach. Int $J$ Obes (Lond) 2011;35:1325-30.

25. Brener ND, McManus T, Galuska DA, et al. Reliability and validity of self-reported height and weight among high school students. J Adolesc Health 2003;32:281-7.
26. Danubio ME, Miranda G, Vinciguerra MG, et al. Comparison of self-reported and measured height and weight: implications for obesity research among young adults. Econ Hum Biol 2008:6:181-90.

27. Rasmussen F, Eriksson M, Nordquist T. Bias in height and weight reported by Swedish adolescents and relations to body dissatisfaction: the COMPASS study. Eur J Clin Nutr 2007;61: 870-6.

28. Livingstone MB, Robson PJ. Measurement of dietary intake in children. Proc Nutr Soc 2000;59:279-93.

29. Paeratakul S, Ferdinand DP, Champagne CM, et al. Fast-food consumption among US adults and children: dietary and nutrient intake profile. J Am Diet Assoc 2003;103:1332-8.

30. Schmidt M, Affenito SG, Striegel-Moore R, et al. Fast-food intake and diet quality in black and white girls: the National Heart, Lung, and Blood Institute Growth and Health Study. Arch Pediatr Adolesc Med 2005;159:626-31.

31. Pereira MA, Kartashov Al, Ebbeling CB, Jr, et al. Fast-food habits, weight gain, and insulin resistance (the CARDIA study): 15-year prospective analysis. Lancet 2005;365:36-42. 